\title{
The importance of intestinal ultrasound and elastographic techniques in inflammatory bowel diseases
}

\author{
Andreea Marin, Laura Tribus, Carmen Fierbinteanu-Braticevici
}

Medical Clinic II Gastroenterology, University Hospital, “Carol Davila” University of Medicine and Pharmacy, Bucharest, Romania.

\begin{abstract}
Inflammatory bowel diseases have an important impact upon the economic and social status due to their increasing incidence and prevalence, often affecting young people. At the moment, the therapeutic goal goes beyond the improvement of symptoms and laboratory parameters, being represented by endoscopic mucosal healing, changing the disease's natural history. Even though endoscopy is the gold standard for the assessment of mucosal healing, it is an invasive maneuver and it lacks good repeatability. These patients require frequent evaluation; therefore, interest for noninvasive techniques has risen. As a consequence, the importance of intestinal ultrasound has increased lately and recent studies support its use to assess the degree of inflammation, to differentiate between remission and relapse, to monitor therapy response and guide treatment, to evaluate prognosis, and to diagnose complications. Another promising noninvasive imagistic technique is elastography which has gained interest because of its capacity to discriminate between inflammatory and fibrotic tissue, taking into account the different therapeutic options for the fibrotic strictures compared to inflammatory processes. This review summarizes the actual recommendations regarding the use of intestinal ultrasound and elastographic techniques for the diagnosis and monitoring of inflammatory bowel diseases.
\end{abstract}

Keywords: inflammatory bowel disease; ultrasound; elastography

\section{Introduction}

Crohn's disease (CD) and ulcerative colitis (UC) are chronic gastrointestinal inflammatory diseases whose clinical course is characterized by periods of remission alternating with relapsing episodes. Inflammatory bowel diseases (IBD) have a huge impact on the social and economic status because they primarily affect young people from urban and industrialized areas. IBD prevalence and incidence have risen during the last decades [1-3] and they are extending even to regions where these epidemiologic parameters used to be low [4].

The diagnosis and monitoring of IBD are based on clinical features, laboratory parameters, colonoscopy,

Received 27.11.2017 Accepted 25.02.2018

Med Ultrason

2018, Vol. 20, No 2, 228-236

Corresponding author: Carmen Fierbinteanu-Braticevici

169 Splaiul Independentei,

Bucharest, Romania, 050098

Phone: +40216912582

E-mail: cfierbinteanu@yahoo.com histopathology, and also on imagistic investigations. Conventional therapeutic strategies are guided by clinical symptoms and biological parameters such as $\mathrm{C}$ reactive protein (CRP) and fecal calprotectin. However, symptomatology does not always correlate with the severity of the disease, meaning that it is not a reliable way of monitoring the treatment $[5,6]$. One of the reasons why symptoms are not solid predictors of the degree of inflammation is that, in a high proportion of IBD patients, symptoms are attributed to irritable bowel syndrome (IBS) [7-9]. In these cases the management is more difficult because the differential diagnosis is challenging for the clinician and can lead to diagnostic confusion [10]. At the same time, other patients are asymptomatic despite the severe, relapsed condition. Moreover, the biological parameters lack good predictability for the severity of IBD $[11,12]$.

At the moment, the therapeutic purpose goes beyond the improvement of symptoms and laboratory markers and is represented by endoscopic mucosal healing [1315]. Even though endoscopy is the gold standard for 
evaluating IBD evolution, the investigation is invasive and not always well tolerated, so it lacks good repeatability. The majority of these patients are young people and require frequent monitoring, considering the course of these disorders; that is why an additional non-invasive, well tolerated and confident diagnostic tool for the assessment of IBD evolution is required. There is no gold standard imagistic technique for the diagnosis and follow-up of IBD, but computed tomography (CT), magnetic resonance imaging (MRI), and ultrasound (US) provide important information regarding intestinal alteration and extraintestinal manifestations [16-18]. Abdominal US techniques have the advantage of being radiationsparing, non-invasive, well tolerated, cheap and easily repeated.

The aim of this review is to provide updated information regarding the use of intestinal US in the diagnosis and follow-up of IBD.

\section{Ultrasound}

Abdominal US has become more and more useful for the diagnosis and the monitoring of IBD. The US examination of the intestine can be done both with the convex array 3-5 MHz probe and with the linear array $5-10 \mathrm{MHz}$ probe for a better evaluation of the 5 layers of the intestinal wall. It should be performed preprandial, in the morning, or at least 6 hours postprandial, when the peristalsis and the luminal air quantity are minimal [19]. The ileocecal region and the sigmoid colon are always visible; the ascendant and descendant colon can be visualized in the majority of cases, but the flexures (mostly the splenic one) are more difficult to assess because they are fixed to the diaphragm by ligaments. Regarding the transverse colon, a complete evaluation is difficult to obtain due to the variable anatomy. The rectum and the anus cannot be properly assessed due to the pelvic location [20,21]. While the terminal ileum is almost always visible, the jejunum and proximal ileum cannot be visualized entirely $[22,23]$. However, a systemic approach of the small intestine is recommended in 4 regions - superior, inferior, right and left quadrants - aiming to identify thickened wall segments [24].

There are many US parameters that characterize IBD: bowel wall thickening, loss of the intestinal wall stratification, and increased transmural vascularization [25-27]. The most important is the thickness of the bowel wall, which is increased as a consequence of inflammation [28-31]. The intestinal wall is considered to be thick if the diameter is more than $3 \mathrm{~mm}$, with a sensitivity of $88 \%$ and a specificity of $93 \%$, but a transmural thickness of more than $4 \mathrm{~mm}$ has a sensitivity and a specificity of
$75 \%$ and $97 \%$, respectively, as an indicator of inflammation [32]. It has been proven that there is a good correlation between transmural diameter, endoscopic findings, and clinical scores such as Crohn Disease Activity Index (CDAI) and Harvey Bradshaw Index (HBI), both for the diagnosis and the monitoring of $\mathrm{CD}$ [33-35]. Even though bowel wall thickness is the most commonly used parameter for intestinal inflammation, at the moment there are no standard measurements, which explains the high interobserver variability. This is not surprising considering that at the moment there is no international consensus regarding the location of the measurements or whether they should be performed transversally or longitudinally [36].

Another US parameter is the intestinal wall architecture, which is usually normal for UC, the 5 layers of the intestinal wall being visible and well differentiated [37]. On the other hand, in the case of $\mathrm{CD}$, the stratification of the intestinal wall can be disorganized as a sign of active inflammation [38]. The evaluation of the surrounding structures is also very important as the proliferation of mesenteric fat tissue near the inflamed bowel is a sign of active CD [37,38]. Usually, these findings totally or partially disappear during remission $[31,39,40]$. However, in remission or quiescent $\mathrm{CD}$, mesenteric fat hypertrophy is not a risk factor for relapse [41]. Increased intramural vascularization is another US parameter for IBD, and it can be evaluated by Doppler ultrasound [42]. It is also a marker of active inflammation and is well correlated with endoscopic findings and CDAI $[35,43]$. The quantification of the degree of inflammation in this case is difficult, considering that the transmural vascularization is related to many factors, including the ingestion of food. Intraperitoneal fluid can be present as a consequence of transmural inflammation $[37,38]$. The finding of enlarged lymph nodes does not correlate with the course of CD, but their presence is strongly associated with the duration of the disease and the existence of internal fistulas [44].

\section{Crohn's Disease}

\section{Diagnosis and complications}

$\mathrm{CD}$ can affect any segment of the gastrointestinal tract, but most frequently it involves the terminal ileum. The small intestine is damaged in $30-40 \%$ of patients and the colon in $40-55 \%$ of the cases [24]. That is why we need a tool to investigate all these segments and the mesenteric structures.

It is well known that intestinal US has high sensitivity and specificity both for the primary diagnosis of $\mathrm{CD}$ [45-48], and for detecting complications such as stenosis, fistulas and abscesses $[25,45,49]$. The global sensitivity of intestinal US for the primary diagnosis of $\mathrm{CD}$ has been 
assessed within many meta-analyses, showing a good diagnostic accuracy. In one of these meta-analyses [50], intestinal US showed sensitivity of $79.7 \%$ and specificity of $96.7 \%$ in diagnosing patients with suspected CD and detected ileal $\mathrm{CD}$ with sensitivity and specificity of $92.7 \%$ and $88.2 \%$, respectively, and colonic CD with $81.8 \%$ sensitivity and $95.3 \%$ specificity. The conclusion is that US has better accuracy for proximal lesions [50]. Another research on patients with suspected CD, which used colonoscopy and MRI as comparative investigations, showed a high diagnostic value of intestinal US, having a sensitivity of $94 \%$, a specificity of $97 \%$, positive predictive value (PPV) 97\%, and negative predictive value (NPV) 94\% [51].

These facts show that intestinal US plays an important role in the diagnosis of $\mathrm{CD}$ within the primary evaluation of patients with symptoms that are suggestive for this condition. Also, having a high negative predictive value, it can rule out $C D$ in subjects with non-specific gastrointestinal symptoms and normal biomarkers such as CRP and fecal calprotectin [51,52]. It has been proven that intestinal US combined with colonoscopy has the highest diagnostic accuracy and is the most cost efficient method compared to MRI for the assessment of patients with suspected CD [53].

The disadvantage of this investigation is the difficult visualization of certain intestinal segments, such as the proximal ileum and the rectum, but this can be improved by using contrast-enhanced ultrasound (CEUS) [54], with a rate of detection increased from $80 \%$ to $100 \%$ mostly in the jejunum $[55,56]$. CEUS showed good sensitivity and specificity for the evaluation of the extension of $\mathrm{CD}$, with pooled sensitivity of $86 \%$, and pooled specificity of 94\% [57].

Intestinal US can also detect the complications of CD: stenosis, fistulas and abscesses, showing good diagnostic accuracy (sensitivity and specificity of $79-100 \%$ and $90-98 \%$ for stenosis, and $71-87 \%$ and $90-96 \%$ for fistulas [49,57-60]). The highest values were registered for the detection of abscesses (sensitivity $90-100 \%$, specificity $92-99 \%$, PPV 90\% and NPV 99\% [49,58]. Therefore, US plays a pivotal role in the detection of abscesses, even though it can produce false positive results [57]. An abscess is characterized by a hypoechoic, irregular, nonperistaltic and nonvascular area which can contain air visible as hyperechoic lines [61].

Stenosis is a common complication of CD and can develop both in the small intestine, and the colon. When performed by experienced clinicians, intestinal US can play a key role in detecting strictures, especially in severe cases that are candidates for surgery. It has been proven that the diagnostic accuracy of strictures increases from
$79 \%$ in patients with mild strictures that can receive medical therapy to $90 \%$ in patients with severe stenosis requiring surgery. In these cases, the sensitivity, specificity and PPV can reach $90 \%, 100 \%$ and $100 \%$, respectively [59]. Colonic stenoses are difficult to be assessed compared with stenoses located in the small intestine [62].

Fistulas are characterized by hypoechoic tracts between the intestinal loops, or between the intestine and other organs, such as the skin, urinary bladder, or vagina. They can contain air visible as hyperechoic areas [38]. Comparing with double contrast barium enema US showed a higher sensitivity for diagnosis internal fistulae. However, it seems that the combination of barium and US studies can reliably detect most internal fistulae [60].

Therefore, intestinal US could be considered as the first line imagistic tool for identifying/excluding the complications of CD. CT and MRI should be used only in case of unclear clinical situations.

\section{Monitoring}

As mentioned above, neither clinical symptoms assessed by HBI, nor biological markers such as CRP and fecal calprotectin, are good indicators of intestinal inflammation and the complications of CD. Symptoms are variable and sometimes are present due to IBS, so guiding the management of these patients by clinical signs and symptoms can lead to either the undertreatment of the asymptomatic subjects, or the overtreatment of overlapped IBS [7,8,63-65].

The actual research data suggests that intestinal US has a pivotal role in monitoring $\mathrm{CD}$ and response to therapy $[31,39,40,66-68]$. There are yet few studies concerning this subject, but the results are promising. Biological treatment with anti TNF- $\alpha$ agents was associated with a significant reduction of the intestinal wall diameter and improvement of the transmural vascularization in $50 \%$ of the patients $[39,69,70]$. All US parameters were improved in patients in remission who also had a significant HBI decrease at 3 months after anti TNF- $\alpha$ therapy initiation, showing a good correlation between US markers and clinical signs and symptoms [40]. In addition, the persistence of these parameters was noted in non-responders in one small study on 24 patients [71]. The improvement of US parameters was correlated with the decrease of CRP levels $[40,66]$ and with endoscopic mucosal healing $[31,39,40]$. Moreover, a recent study performed in pediatric patients with small bowel CD showed a strong correlation between bowel wall Doppler signal and the level of fecal calprotectin [68].

Lately, it has been highlighted that colonoscopy can be replaced with noninvasive techniques, such as Doppler ultrasound or CEUS, for the diagnosis of relapsed 
CD, but more studies are required [39,54,72-75]. Doppler examination of the vascularization of thickened bowel wall is useful for the differentiation of relapse from remission and is well correlated with endoscopic findings both in adults, and children [35,43,71]. For the evaluation of microvascularization, CEUS accuracy is comparable to MRI accuracy and superior to Doppler ultrasound [76]. CEUS can be a useful tool to monitor the activity of $\mathrm{CD}$, mostly ileal $\mathrm{CD}$, as it is correlated with the severity grade assessed by endoscopy $[73,77]$. Also, it is effective in distinguishing inflammatory from fibrostenotic lesions, so it can provide prognostic information and guide further management $[78,79]$. However, its importance regarding IBD is still unclear, and more research is needed $[80,81]$.

There are studies that have investigated the impact of intestinal US on clinical decision making. The management of the patients included in this research was changed after performing intestinal US in $60 \%$ of the cases; $59 \%$ of the subjects were asymptomatic, with $\mathrm{HBI} \leq 3$, even though $52 \%$ of them had relapsed disease US visible. The most frequent decision was changing the medication (in $45 \%$ of the cases), followed by the request for supplementary investigations in $24 \%$ of the cases. In $14 \%$ of the subjects, the clinician asked for a surgeon opinion and $4 \%$ of patient were admitted [82].

Abdominal US can play an essential role in monitoring the evolution of postoperative $\mathrm{CD}$ recurrence as well [83-85]. At the moment, endoscopy is the gold standard tool in this situation, but lately, US has provided significant credit, with a sensitivity of $89.7 \%$ for the detection of recurrent postoperative disease which can be increased by CEUS to $98 \%$ [69].

In conclusion, there is clear evidence regarding the benefits of US for the evaluation of transmural inflammation, complications and extraintestinal manifestations of CD. Moreover, the severity of US findings, particularly a significant increase in transmural thickness, can be a good predictor for the necessity of a surgical intervention $[82,86]$. US can be considered a surrogate investigation of endoscopy for the assessment of mucosal healing after biological therapy initiation [87]. Early detection of inflammatory activity is an important step in guiding the treatment, in preventing complications and hospitalization, and in improving the quality of life; clinicians should, therefore, integrate abdominal US in the routine investigations of these patients.

\section{Ulcerative colitis}

In UC, the inflammation is limited to the colon, with a particular, continuous, distal to proximal disposition.
Apart from in the rectal location, generally the lesions cannot be visualized by US due to the pelvic position of the rectum [24]. The role of abdominal US in UC is not as well defined as in $\mathrm{CD}$, mostly because the bowel wall is not always thickened, the inflammation is limited to the mucosa and the bowel wall stratification is preserved in most of the subjects $[38,88]$.

However, thickening of the mucosa is a characteristic of edema during active inflammation in UC, even though it is not always evident on US. Unlike CD, thickening of the intestinal wall is not constantly correlated with the clinical activity of the disease in UC [88]. While in cases of mild relapse there is no or inconsistent concordance between the bowel wall thickness and clinical and endoscopic scores, in moderate or severe UC, bowel wall thickness can be used as a surrogate for colonoscopy and CRP for monitoring the course of the disease and the response to therapy $[89,90]$.

The role of US for monitoring patients with UC is still not well established, as there is little data regarding the evolution of the intestinal wall thickness following treatment. Nonetheless, the actual evidence suggests that US findings, bowel wall thickness in particular, correlates with clinical and endoscopic scores both before and after therapy; the results of the studies suggested the effectiveness of US in evaluating treatment response as well as in assessing UC extension [91,92]. It has been pointed out that the US aspect of the intestine after 3 months of therapy can predict the outcome of UC at 15 months, as accurately as endoscopic scores [89,92]. Also, some studies suggest that Doppler US of the superior and inferior mesenteric arteries can be used for assessing the disease severity and the relapsing risk $[93,94]$.

The other US parameters of IBD, such as the intestinal wall vascularization and fibrofatty proliferation, are less visible in UC compared to CD [24,88]. However, in severe active forms of UC, extramural signs such as fibrofatty proliferation, peritoneal fluid, and even "mesenteric lines" can be visible, even though most of the time, this condition is largely limited to the mucosa [38].

\section{Elastography}

In addition to intestinal US, CT and MRI, there is great interest in elastographic techniques for the assessment of patients with UC. Even though there is little data available, the first results in this direction are promising, suggesting the ability of elastography to differentiate between inflammatory and fibrotic tissue, which is crucial for the management of these patients [95-98]. Fibrosis develops in time as a consequence of chronic inflammation and has a major influence on IBD morbidity, as it 
is associated with high rates of hospitalization and surgical interventions [99]. The opportunity to evaluate the proportion of fibrotic and inflammatory tissue is an important step for the non-invasive management of $\mathrm{CD}$, considering that the presence of fibrotic tissue negatively influences the response to biological treatment and results in the need for endoscopic or surgical treatment [99102].

Animal model studies have shown good accuracy of strain elastography (SE) for the measurement of intestinal wall stiffness, confirming that the degree of stiffness correlates with the proportion of fibrotic tissue [103]. Another study showed strong concordance between elastographic values and the direct measurement of the bowel wall stiffness after surgical resection performed on mice with CD strictures [104]. Recent human model research suggests that the affected segments of the intestine have a higher strain than the normal ones both on elastographic, and on direct measurements $[98,101,105]$. Moreover, comparing the SE results with histologic features, the strain values correlate with the histologic characteristics of fibrosis, such as collagen and muscular fibers deposits $[101,102]$. The assessment of intestinal fibrosis and the differentiation of inflammation from fibrosis have been studied using a semi quantitative visual color scale and the strain ratio (SR) which is the ratio between the mean strain in the normal intestinal tissue near the lesions and the mean strain of the affected intestinal tissue [106]. SR demonstrated a good ability to diagnose severe intestinal fibrosis, but failed to differentiate the degree of inflammation [102].

However, SE is not routinely performed in clinical practice as there are few reported studies on this issue. Moreover, it is not useful in differentiating CD from other gastrointestinal disorders [106,107].

Even though shear wave elastography (SWE) is considered to be superior to SE because it is simpler and more reproducible, there is not much information regarding its use for IBD. However, animal model studies have shown that SWE values were higher for fibrosis than for acute inflammation, and the AUROC curve of shear wave speed ratio (mean shear wave speed/applied tension) for the differential diagnosis between fibrosis and inflammation was very good (0.971), suggesting that this noninvasive imagistic method can be successfully used in clinical practice [108]. A recent study performed on 17 intestinal specimens surgically resected from patients with known or suspected IBD showed a good capacity of SWE to discriminate between high-grade fibrotic areas and mild fibrosis areas. However, there was no correlation between shear wave velocity and the degree of inflammation. Moreover, this study provided no informa- tion regarding the differential diagnosis between fibrosis and inflammation [95]. Some data reported SWE as being able to discriminate between active and chronic intestinal inflammation in case of strictures, thus improving the management of these patients by helping decide between medical therapy and surgery $[98,109]$. Therefore, the utility of SWE for the assessment of IBD is not yet known and more data is needed to validate this investigation $[98,99]$.

There are some limits regarding the use of elastographic techniques for the intestinal wall: the intestine cannot be visualized entirely and the peristalsis can cause errors (which does not occur in parenchymal organs). However, nowadays, there are many software programs that can help minimalize such errors. On the other hand, elastographic techniques have the advantages of being noninvasive, easily accepted by patients and cost efficient, features which seem to overcome the eventual limits [99].

\section{Conclusions}

At the moment, intestinal US is accepted as a first line imagistic tool for the diagnosis and monitoring of IBD and is included in the ECCO guidelines. Despite scarce data, elastographic techniques have had promising results concerning IBD assessment, primarily as regards estimation of the amount of fibrosis and inflammation in bowel strictures The most recent gastrointestinal ultrasound guideline recommends the use of elastographic techniques to evaluate the stiffness of thickened bowel wall. However, further studies are required for the validation of elastography in the assessment of the intestinal wall.

\section{Conflict of interest: none}

\section{References}

1. Cosnes J, Gower-Rousseau C, Seksik P, Cortot A. Epidemiology and natural history of inflammatory bowel diseases. Gastroenterology 2011;140:1785-1794.

2. Molodecky NA, Soon IS, Rabi DM, et al. Increasing incidence and prevalence of the inflammatory bowel diseases with time, based on systematic review. Gastroenterology 2012;142:46-54.

3. Ng SC, Shi HY, Hamidi N, et al. Worldwide incidence and prevalence of inflammatory bowel disease in the 21 st century: a systematic review of population-based studies. Lancet 2018;390:2769-2778.

4. Gomez-Gomez GJ, Masedo A, Yela C, Martinez-Montiel Mdel P, Casis B. Current stage in inflammatory bowel disease: What is next? World J Gastroenterol 2015;21:1128211303 . 
5. Schoepfer AM, Vavricka S, Zahnd-Straumann N, Straumann A, Beglinger C. Monitoring inflammatory bowel disease activity: clinical activity is judged to be more relevant than endoscopic severity or biomarkers. J Crohns Colitis 2012;6:412-418

6. Falvey JD, Hoskin T, Meijer B, et al. Disease activity assessment in IBD: clinical indices and biomarkers fail to predict endoscopic remission. Inflamm Bowel Dis 2015;21:824-831.

7. Halpin SJ, Ford AC. Prevalence of symptoms meeting criteria for irritable bowel syndrome in inflammatory bowel disease: systematic review and meta-analysis. Am J Gastroenterol 2012;107:1474-1482.

8. Berrill JW, Green JT, Hood K, Campbell AK. Symptoms of irritable bowel syndrome in patients with inflammatory bowel disease: examining the role of sub-clinical inflammation and the impact on clinical assessment of disease activity. Aliment Pharmacol Ther 2013;38:44-51.

9. Jonefjall B, Strid H, Ohman L, Svedlund J, Bergstedt A, Simren M. Characterization of IBS-like symptoms in patients with ulcerative colitis in clinical remission. Neurogastroenterol Motil 2013;25:756-e578.

10. Quigley EM, Bernstein CN. "Irritable bowel symptoms" in inflammatory bowel disease: diagnostic uncertainty meets pathological reality. Am J Gastroenterol 2012;107:14831485.

11. Tibble JA, Sigthorsson G, Bridger S, Fagerhol MK, Bjarnason I. Surrogate markers of intestinal inflammation are predictive of relapse in patients with inflammatory bowel disease. Gastroenterology 2000;119:15-22.

12. Chang S, Malter L, Hudesman D. Disease monitoring in inflammatory bowel disease. World J Gastroenterol 2015;21:11246-11259.

13. Sandborn WJ, Hanauer S, Van Assche G, et al. Treating beyond symptoms with a view to improving patient outcomes in inflammatory bowel diseases. J Crohns Colitis 2014;8:927-935.

14. Hazlewood GS, Rezaie A, Borman M, et al. Comparative effectiveness of immunosuppressants and biologics for inducing and maintaining remission in Crohn's disease: a network meta-analysis. Gastroenterology 2015;148:344354.

15. Frolkis AD, Dykeman J, Negron ME, et al. Risk of surgery for inflammatory bowel diseases has decreased over time: a systematic review and meta-analysis of population-based studies. Gastroenterology 2013;145:996-1006.

16. Puylaert CA, Tielbeek JA, Bipat S, Stoker J. Grading of Crohn's disease activity using CT, MRI, US and scintigraphy: a meta-analysis. Eur Radiol 2015;25:3295-3313.

17. Zakeri N, Pollok RC. Diagnostic imaging and radiation exposure in inflammatory bowel disease. World J Gastroenterol 2016;22:2165-2178.

18. Greenup AJ, Bressler B, Rosenfeld G. Medical Imaging in Small Bowel Crohn's Disease-Computer Tomography Enterography, Magnetic Resonance Enterography, and Ultrasound: "Which One Is the Best for What?". Inflamm Bowel Dis 2016;22:1246-1261.
19. Panes J, Bouhnik Y, Reinisch W, et al. Imaging techniques for assessment of inflammatory bowel disease: joint ECCO and ESGAR evidence-based consensus guidelines. J Crohns Colitis 2013;7:556-585.

20. Ordas I, Rimola J, Rodriguez S, Gallego M, Ricart E, Panes $\mathrm{J}$. Imaging of the colon in inflammatory bowel disease: ready for prime time? Curr Drug Targets 2012;13:1252-1260.

21. Bor R, Fabian A, Szepes Z. Role of ultrasound in colorectal diseases. World J Gastroenterol 2016;22:9477-9487.

22. Hollerbach S, Geissler A, Schiegl H, et al. The accuracy of abdominal ultrasound in the assessment of bowel disorders. Scand J Gastroenterol 1998;33:1201-1208.

23. Parente F, Greco S, Molteni M, et al. Role of early ultrasound in detecting inflammatory intestinal disorders and identifying their anatomical location within the bowel. Aliment Pharmacol Ther 2003;18:1009-1016.

24. Strobel D, Goertz RS, Bernatik T. Diagnostics in inflammatory bowel disease: ultrasound. World J Gastroenterol 2011;17:3192-3197.

25. Poza-Cordon J, Ripolles-Gonzalez T. Utility of abdominal ultrasonography in the diagnosis and monitoring of inflammatory bowel disease. Rev Esp Enferm Dig 2014;106:395408.

26. Allgayer H, Braden B, Dietrich CF. Transabdominal ultrasound in inflammatory bowel disease. Conventional and recently developed techniques--update. Med Ultrason 2011;13:302-313.

27. Conti CB, Giunta M, Gridavilla D, Conte D, Fraquelli M. Role of Bowel Ultrasound in the Diagnosis and Follow-up of Patients with Crohn's Disease. Ultrasound Med Biol 2017;43:725-734.

28. Haber HP, Busch A, Ziebach R, Stern M. Bowel wall thickness measured by ultrasound as a marker of Crohn's disease activity in children. Lancet 2000;355:1239-1240.

29. Haber HP, Busch A, Ziebach R, Dette S, Ruck P, Stern M. Ultrasonographic findings correspond to clinical, endoscopic, and histologic findings in inflammatory bowel disease and other enterocolitides. J Ultrasound Med 2002;21:375382.

30. Chiorean L, Schreiber-Dietrich D, Braden B, Cui X, Dietrich CF. Transabdominal ultrasound for standardized measurement of bowel wall thickness in normal children and those with Crohn's disease. Med Ultrason 2014;16:319324.

31. Novak KL, Kaplan GG, Panaccione R, et al. A Simple Ultrasound Score for the Accurate Detection of Inflammatory Activity in Crohn's Disease. Inflamm Bowel Dis 2017;23:2001-2010.

32. Fraquelli M, Colli A, Casazza G, et al. Role of US in detection of Crohn disease: meta-analysis. Radiology 2005;236:95-101.

33. Calabrese E, Petruzziello C, Onali S, et al. Severity of postoperative recurrence in Crohn's disease: correlation between endoscopic and sonographic findings. Inflamm Bowel Dis 2009;15:1635-1642.

34. Rigazio C, Ercole E, Laudi C, et al. Abdominal bowel ultrasound can predict the risk of surgery in Crohn's disease: 
proposal of an ultrasonographic score. Scand J Gastroenterol 2009;44:585-593.

35. Drews BH, Barth TF, Hanle MM, et al. Comparison of sonographically measured bowel wall vascularity, histology, and disease activity in Crohn's disease. Eur Radiol 2009;19:1379-1386.

36. Calabrese E, Kucharzik T, Maaser C, et al. Sa2028 Interobserver agreement in bowel ultrasonography for diagnostic assessment in patients with Crohn's disease. Gastroenterology 2016;150:S433-S434.

37. Kilcoyne A, Kaplan JL, Gee MS. Inflammatory bowel disease imaging: Current practice and future directions. World J Gastroenterol 2016;22:917-932.

38. Kucharzik T, Kannengiesser K, Petersen F. The use of ultrasound in inflammatory bowel disease. Ann Gastroenterol 2017;30:135-144.

39. Moreno N, Ripolles T, Paredes JM, et al. Usefulness of abdominal ultrasonography in the analysis of endoscopic activity in patients with Crohn's disease: changes following treatment with immunomodulators and/or anti-TNF antibodies. J Crohns Colitis 2014;8:1079-1087.

40. Kucharzik T, Wittig BM, Helwig U, et al. Use of Intestinal Ultrasound to Monitor Crohn's Disease Activity. Clin Gastroenterol Hepatol 2017;15:535-542.

41. Maconi G, Greco S, Duca P, et al. Prevalence and clinical significance of sonographic evidence of mesenteric fat alterations in Crohn's disease. Inflamm Bowel Dis 2008;14:1555-1561.

42. Sasaki T, Kunisaki R, Kinoshita H, et al. Doppler ultrasound findings correlate with tissue vascularity and inflammation in surgical pathology specimens from patients with small intestinal Crohn's disease. BMC Res Notes 2014;7:363.

43. Neye H, Voderholzer W, Rickes S, Weber J, Wermke W, Lochs H. Evaluation of criteria for the activity of Crohn's disease by power Doppler sonography. Dig Dis 2004;22:67-72.

44. Maconi G, Di Sabatino A, Ardizzone S, et al. Prevalence and clinical significance of sonographic detection of enlarged regional lymph nodes in Crohn's disease. Scand J Gastroenterol 2005;40:1328-1333.

45. Calabrese E, Zorzi F, Pallone F. Ultrasound in Crohn's disease. Curr Drug Targets 2012;13:1224-1233.

46. Dong J, Wang H, Zhao J, et al. Ultrasound as a diagnostic tool in detecting active Crohn's disease: a meta-analysis of prospective studies. Eur Radiol 2014;24:26-33.

47. Ziech ML, Hummel TZ, Smets AM, et al. Accuracy of abdominal ultrasound and MRI for detection of Crohn disease and ulcerative colitis in children. Pediatr Radiol 2014;44:1370-1378.

48. Tsai TL, Marine MB, Wanner MR, et al. Can ultrasound be used as the primary imaging in children with suspected Crohn disease? Pediatr Radiol 2017;47:917-923.

49. Neye H, Ensberg D, Rauh P, et al. Impact of high-resolution transabdominal ultrasound in the diagnosis of complications of Crohn's disease. Scand J Gastroenterol 2010;45:690-695.

50. Calabrese E, Maaser C, Zorzi F, et al. Bowel Ultrasonography in the Management of Crohn's Disease. A Review with
Recommendations of an International Panel of Experts. Inflamm Bowel Dis 2016;22:1168-1183.

51. Castiglione F, Mainenti PP, De Palma GD, et al. Noninvasive diagnosis of small bowel Crohn's disease: direct comparison of bowel sonography and magnetic resonance enterography. Inflamm Bowel Dis 2013;19:991-998.

52. Solvig J, Ekberg O, Lindgren S, Floren CH, Nilsson P. U1trasound examination of the small bowel: comparison with enteroclysis in patients with Crohn disease. Abdom Imaging 1995;20:323-326.

53. Maconi G, Bolzoni E, Giussani A, Friedman AB, Duca P. Accuracy and cost of diagnostic strategies for patients with suspected Crohn's disease. J Crohns Colitis 2014;8:16841692.

54. Ma X, Li Y, Jia H, et al. Contrast-enhanced ultrasound in the diagnosis of patients suspected of having active Crohn's disease: meta-analysis. Ultrasound Med Biol 2015;41:659668.

55. Parente F, Greco S, Molteni M, Anderloni A, Bianchi Porro G. Imaging inflammatory bowel disease using bowel ultrasound. Eur J Gastroenterol Hepatol 2005; 17:283-291.

56. Parente F, Greco S, Molteni M, et al. Oral contrast enhanced bowel ultrasonography in the assessment of small intestine Crohn's disease. A prospective comparison with conventional ultrasound, $x$ ray studies, and ileocolonoscopy. Gut 2004;53:1652-1657.

57. Panes J, Bouzas R, Chaparro M, et al. Systematic review: the use of ultrasonography, computed tomography and magnetic resonance imaging for the diagnosis, assessment of activity and abdominal complications of Crohn's disease. Aliment Pharmacol Ther 2011;34:125-145.

58. Gasche C, Moser G, Turetschek K, Schober E, Moeschl P, Oberhuber G. Transabdominal bowel sonography for the detection of intestinal complications in Crohn's disease. Gut 1999;44:112-117.

59. Parente F, Maconi G, Bollani S, et al. Bowel ultrasound in assessment of Crohn's disease and detection of related small bowel strictures: a prospective comparative study versus $x$ ray and intraoperative findings. Gut 2002;50:490495.

60. Maconi G, Sampietro GM, Parente F, et al. Contrast radiology, computed tomography and ultrasonography in detecting internal fistulas and intra-abdominal abscesses in Crohn's disease: a prospective comparative study. Am J Gastroenterol 2003;98:1545-1555.

61. Ripolles T, Martinez-Perez MJ, Paredes JM, Vizuete J, Garcia-Martinez E, Jimenez-Restrepo DH. Contrast-enhanced ultrasound in the differentiation between phlegmon and abscess in Crohn's disease and other abdominal conditions. Eur J Radiol 2013;82:e525-e531.

62. Maconi G, Bollani S, Bianchi Porro G. Ultrasonographic detection of intestinal complications in Crohn's disease. Dig Dis Sci 1996;41:1643-1648.

63. Lahiff C, Safaie P, Awais A, et al. The Crohn's disease activity index (CDAI) is similarly elevated in patients with Crohn's disease and in patients with irritable bowel syndrome. Aliment Pharmacol Ther 2013;37:786-794. 
64. Meng J, Agrawal A, Whorwell PJ. Refractory inflammatory bowel disease-could it be an irritable bowel? Nat Rev Gastroenterol Hepatol 2013;10:58-61.

65. Burgell RE, Asthana AK, Gibson PR. Irritable bowel syndrome in quiescent inflammatory bowel disease: a review. Minerva Gastroenterol Dietol 2015;61:201-213.

66. Socaciu M, Ciobanu L, Diaconu B, Hagiu C, Seicean A, Badea R. Non-Invasive Assessment of Inflammation and Treatment Response in Patients with Crohn's Disease and Ulcerative Colitis using Contrast-Enhanced Ultrasonography Quantification. J Gastrointestin Liver Dis2015;24:457465.

67. Wilkens R, Novak KL, Lebeuf-Taylor E, Wilson SR. Impact of Intestinal Ultrasound on Classification and Management of Crohn's Disease Patients with Inconclusive Colonoscopy. Can J Gastroenterol Hepatol 2016;2016:8745972.

68. Dillman JR, Dehkordy SF, Smith EA, et al. Defining the ultrasound longitudinal natural history of newly diagnosed pediatric small bowel Crohn disease treated with infliximab and infliximab-azathioprine combination therapy. Pediatr Radiol 2017;47:924-934.

69. Paredes JM, Ripolles T, Cortes X, et al. Contrast-enhanced ultrasonography: usefulness in the assessment of postoperative recurrence of Crohn's disease. J Crohns Colitis 2013;7:192-201.

70. Paredes JM, Ripolles T, Cortes X, et al. Abdominal sonographic changes after antibody to tumor necrosis factor (anti-TNF) alpha therapy in Crohn's Disease. Dig Dis Sci 2010;55:404-410.

71. Spalinger J, Patriquin H, Miron MC, et al. Doppler US in patients with crohn disease: vessel density in the diseased bowel reflects disease activity. Radiology 2000;217:787791.

72. Sasaki T, Kunisaki R, Kinoshita H, et al. Use of color Doppler ultrasonography for evaluating vascularity of small intestinal lesions in Crohn's disease: correlation with endoscopic and surgical macroscopic findings. Scand J Gastroenterol 2014;49:295-301.

73. De Franco A, Di Veronica A, Armuzzi A, et al. Ileal Crohn disease: mural microvascularity quantified with contrastenhanced US correlates with disease activity. Radiology 2012;262:680-688.

74. Quaia E. Contrast-enhanced ultrasound of the small bowel in Crohn's disease. Abdom Imaging 2013;38:1005-1013.

75. Saevik F, Nylund K, Hausken T, Odegaard S, Gilja OH. Bowel perfusion measured with dynamic contrast-enhanced ultrasound predicts treatment outcome in patients with Crohn's disease. Inflamm Bowel Dis 2014;20:2029-2037.

76. Horjus Talabur Horje CS, Bruijnen R, Roovers L, Groenen MJ, Joosten FB, Wahab PJ. Contrast Enhanced Abdominal Ultrasound in the Assessment of Ileal Inflammation in Crohn's Disease: A Comparison with MR Enterography. PLoS One 2015;10:e136105.

77. Ripolles T, Martinez MJ, Paredes JM, Blanc E, Flors L, Delgado F. Crohn disease: correlation of findings at contrast-enhanced US with severity at endoscopy. Radiology 2009;253:241-248.
78. Ripolles T, Rausell N, Paredes JM, Grau E, Martinez MJ, Vizuete J. Effectiveness of contrast-enhanced ultrasound for characterisation of intestinal inflammation in Crohn's disease: a comparison with surgical histopathology analysis. J Crohns Colitis 2013;7:120-128.

79. Nylund K, Jirik R, Mezl M, et al. Quantitative contrast-enhanced ultrasound comparison between inflammatory and fibrotic lesions in patients with Crohn's disease. Ultrasound Med Biol 2013;39:1197-1206.

80. Wong DD, Forbes GM, Zelesco M, Mason R, Pawlik J, Mendelson RM. Crohn's disease activity: quantitative contrast-enhanced ultrasound assessment. Abdom Imaging 2012;37:369-376.

81. Serafin Z, Bialecki M, Bialecka A, Sconfienza LM, Klopocka M. Contrast-enhanced Ultrasound for Detection of Crohn's Disease Activity: Systematic Review and Metaanalysis. J Crohns Colitis 2016;10:354-362.

82. Novak K, Tanyingoh D, Petersen F, et al. Clinic-based Point of Care Transabdominal Ultrasound for Monitoring Crohn's Disease: Impact on Clinical Decision Making. J Crohns Colitis 2015;9:795-801.

83. Andreoli A, Cerro P, Falasco G, Giglio LA, Prantera C. Role of ultrasonography in the diagnosis of postsurgical recurrence of Crohn's disease. Am J Gastroenterol 1998;93:1117-1121.

84. Maconi G, Sampietro GM, Sartani A, Bianchi Porro G. Bowel ultrasound in Crohn's disease: surgical perspective. Int J Colorectal Dis 2008;23:339-347.

85. Cammarota T, Ribaldone DG, Resegotti A, et al. Role of bowel ultrasound as a predictor of surgical recurrence of Crohn's disease. Scand J Gastroenterol 2013;48:552-555.

86. Castiglione F, de Sio I, Cozzolino A, et al. Bowel wall thickness at abdominal ultrasound and the one-year-risk of surgery in patients with Crohn's disease. Am J Gastroenterol 2004;99:1977-1983.

87. Castiglione F, Testa A, Rea M, et al. Transmural healing evaluated by bowel sonography in patients with Crohn's disease on maintenance treatment with biologics. Inflamm Bowel Dis 2013;19:1928-1934.

88. Dietrich CF. Significance of abdominal ultrasound in inflammatory bowel disease. Dig Dis 2009;27:482-493.

89. Parente F, Molteni M, Marino B, et al. Bowel ultrasound and mucosal healing in ulcerative colitis. Dig Dis 2009;27:285-290.

90. Antonelli E, Giuliano V, Casella G, et al. Ultrasonographic assessment of colonic wall in moderate-severe ulcerative colitis: comparison with endoscopic findings. Dig Liver Dis 2011;43:703-706.

91. Maconi G, Ardizzone S, Parente F, Bianchi Porro G. Ultrasonography in the evaluation of extension, activity, and follow-up of ulcerative colitis. Scand J Gastroenterol 1999;34:1103-1107.

92. Parente F, Molteni M, Marino B, et al. Are colonoscopy and bowel ultrasound useful for assessing response to shortterm therapy and predicting disease outcome of moderateto-severe forms of ulcerative colitis?: a prospective study. Am J Gastroenterol 2010;105:1150-1157. 
93. Ludwig D, Wiener S, Bruning A, et al. Mesenteric blood flow is related to disease activity and risk of relapse in ulcerative colitis: a prospective follow up study. Gut 1999;45:546-552.

94. Sigirci A, Baysal T, Kutlu R, Aladag M, Sarac K, Harputluoglu H. Doppler sonography of the inferior and superior mesenteric arteries in ulcerative colitis. J Clin Ultrasound 2001;29:130-139.

95. Dillman JR, Stidham RW, Higgins PD, et al. Ultrasound shear wave elastography helps discriminate low-grade from high-grade bowel wall fibrosis in ex vivo human intestinal specimens. J Ultrasound Med 2014;33:21152123.

96. Serra C, Rizzello F, Pratico C, et al. Real-time elastography for the detection of fibrotic and inflammatory tissue in patients with stricturing Crohn's disease. J Ultrasound 2017;20:273-284.

97. Quaia E, Gennari AG, Cova MA, van Beek EJR. Differentiation of Inflammatory From Fibrotic Ileal Strictures among Patients with Crohn's Disease Based on Visual Analysis: Feasibility Study Combining Conventional BMode Ultrasound, Contrast-Enhanced Ultrasound and Strain Elastography. Ultrasound Med Biol 2018;44:762770.

98. Pescatori LC, Mauri G, Savarino E, Pastorelli L, Vecchi M, Sconfienza LM. Bowel Sonoelastography in Patients with Crohn's Disease: A Systematic Review. Ultrasound Med Biol 2018;44:297-302.

99. Branchi F, Caprioli F, Orlando S, Conte D, Fraquelli M. Non-invasive evaluation of intestinal disorders: The role of elastographic techniques. World J Gastroenterol 2017;23:2832-2840.

100. Nylund K, Maconi G, Hollerweger A, et al. EFSUMB Recommendations and Guidelines for Gastrointestinal Ultrasound. Ultraschall Med 2017;38:e1-e15.
101. Baumgart DC, Muller HP, Grittner U, et al. US-based Real-time Elastography for the Detection of Fibrotic Gut Tissue in Patients with Stricturing Crohn Disease. Radiology 2015;275:889-899.

102. Fraquelli M, Branchi F, Cribiu FM, et al. The Role of Ultrasound Elasticity Imaging in Predicting Ileal Fibrosis in Crohn's Disease Patients. Inflamm Bowel Dis 2015;21:2605-2612.

103. 103.Kim K, Johnson LA, Jia C, et al. Noninvasive ultrasound elasticity imaging (UEI) of Crohn's disease: animal model. Ultrasound Med Biol 2008;34:902-912.

104. Stidham RW, Xu J, Johnson LA, et al. Ultrasound elasticity imaging for detecting intestinal fibrosis and inflammation in rats and humans with Crohn's disease. Gastroenterology 2011;141:819-826.

105. Fufezan O, Asavoaie C, Tamas A, Farcau D, Serban D. Bowel elastography - a pilot study for developing an elastographic scoring system to evaluate disease activity in pediatric Crohn's disease. Med Ultrason 2015;17:422-430.

106. Giannetti A, Matergi M, Biscontri M, Tedone F, Falconi L, Franci L. Real-time elastography in Crohn's disease: feasibility in daily clinical practice. J Ultrasound 2017;20:147-155.

107. Giannetti A, Biscontri M, Matergi M. Feasibility of realtime strain elastography in colonic diseases. J Ultrasound 2014;17:321-330.

108. Dillman JR, Stidham RW, Higgins PD, Moons DS, Johnson LA, Rubin JM. US elastography-derived shear wave velocity helps distinguish acutely inflamed from fibrotic bowel in a Crohn disease animal model. Radiology 2013;267:757-766.

109. Lu C, Gui X, Chen W, Fung T, Novak K, Wilson SR. Ultrasound Shear Wave Elastography and Contrast Enhancement: Effective Biomarkers in Crohn's Disease Strictures. Inflamm Bowel Dis 2017;23:421-430. 